\title{
Assessment of differential subsidence harmful effects on large bridge structures during the underground space development
}

\author{
V.I. Kireeva ${ }^{1}$, E.M. Volokhov $^{2}$, M.O. Lebedev ${ }^{3}$ \\ ${ }^{1}$ Saint-Petersburg Mining University, Department of Mine Surveying, Saint-Petersburg Mining \\ University, St. Petersburg, Russia \\ ${ }^{2}$ Design and Survey Institute "Lenmetrogiprotrans", Deputy Director General for Research, JSC \\ Scientific Research, , St. Petersburg, Russia
}

\begin{abstract}
The purpose of the study was to confirm the capability of numerical simulation of soils shift and bridge structures elements deformations during underground construction. The main goal of this simulation was to assess the harmful effects of mining operations on the existing bridge load-bearing elements. Modeling of bridge structures undermining by earth pressure balance tunneling boring machines (EPB TBMs) was carried out both at the design stage for predicting deformations and at the stage of underground work completion.
\end{abstract}

\section{INTRODUCTION}

The problem of undermining bridge structures is urgent, first of all, because of the lack of reference documents, which should regulate the assessment of the degree of impact during the tunneling operations. There is also no regulation of monitoring of displacements and deformations.

Bridge structures undermining issues were investigated by The All-Russian Research In-stitute of Mining Geomechanics and Survey and The Ural Branch of the Russian Academy of Sciences. The results of the institutes' work are reflected in reference documents $[1,2]$, which are one of the few that regulate the assessment of the harmful effects during the bridge structures undermining.

The lack of a regulatory framework for assessing the bridge structures undermining during underground construction leads to the need for special research. In recent decades, methods of mathematical simulation have become widely used for displacement and deformation assessment [3-8]. Sometimes it is used in combination with physical and centrifuge modeling [9].

One of the most common types of mathematical simulation for assessing the impact of underground construction on bridge structures is the finite element method (FEM) [10, 11, 12]. At the same time, to obtain reliable results, not only on a qualitative but also on a quantitative level, model verification based on field data is necessary.

In 2017, during the construction of a double-track running tunnel in St. Petersburg (Nevsky-Vasileostrovskaya metro line), a bridge section of the Western High-Speed Diameter (WHSD) was undermined. The tunneling was carried out by earth pressure 
balance tunneling boring machine (EPB TBM). The construction speed and the EPB technological modes were relatively stable (there were no stops) at this trace link. An EPB of this class, as the practice has shown, can provide the geomechanical state control of soil formations. However, both subsidence and long-term elevations can occur on the surface [13].

\section{METHODS}

\subsection{Simulation of bridge structures undermining}

According to the design, the running tunnel trace crossed the main trace of the WHSD facilities at an acute angle $\left(45^{\circ}-50^{\circ}\right)$ (Fig. 1).

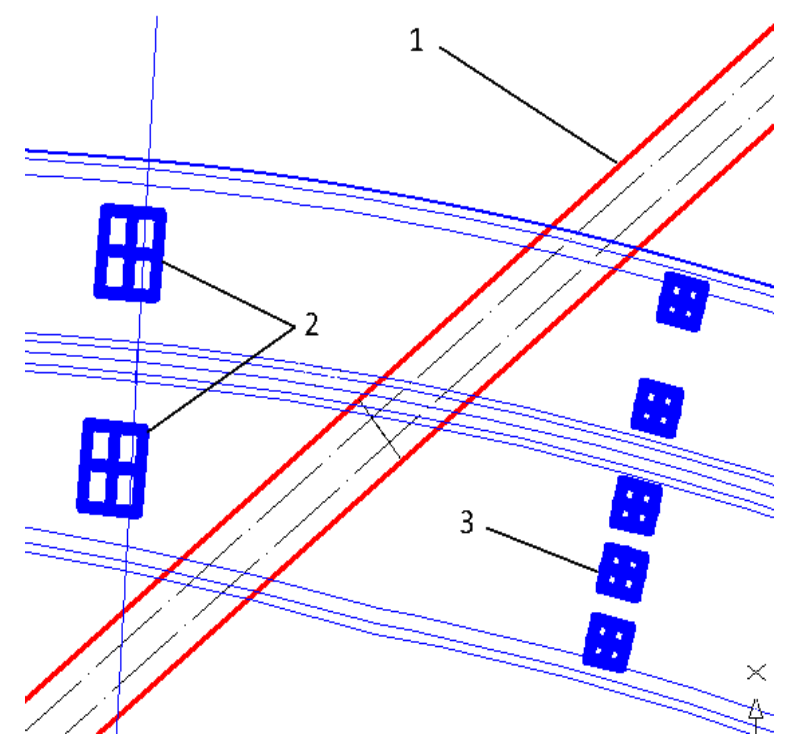

Fig. 1. Scheme of the running tunnel and the intersection of the WHSD elements: 1- subway tunnel; 2 - V9 group piers; 3 - V8 group piers.

The tunnel was built in Proterozoic bedrock (the depth of the tunnel axis in this area was about 47 meters). The bored pile foundations of the bridges are located above the tunnel.

Support foundations are bored piles $1.2 \mathrm{~m}$ in diameter (V9 group piers) and $1.5 \mathrm{~m}$ (V8 group piers) buried to the level of bedrock and reinforced concrete grillages. The upper part of the pier foundations is in bulk (alluvial) soils. At the intersection of the running tunnel trace and the WHSD, there are two V9 group piers and five V8 group piers.

The foundations of the V9-group piers were designed in the form of twelve piles groups, united by a foundation grill (2.5 meters thick). The depth of the piles is 29.1 meters (Fig. 2). The foundations of the V8 group piers were designed in the form of four pile groups, united by a foundation grill ( 2 meters thick). The depth of the piles is 30.4 meters (Fig. 3). 


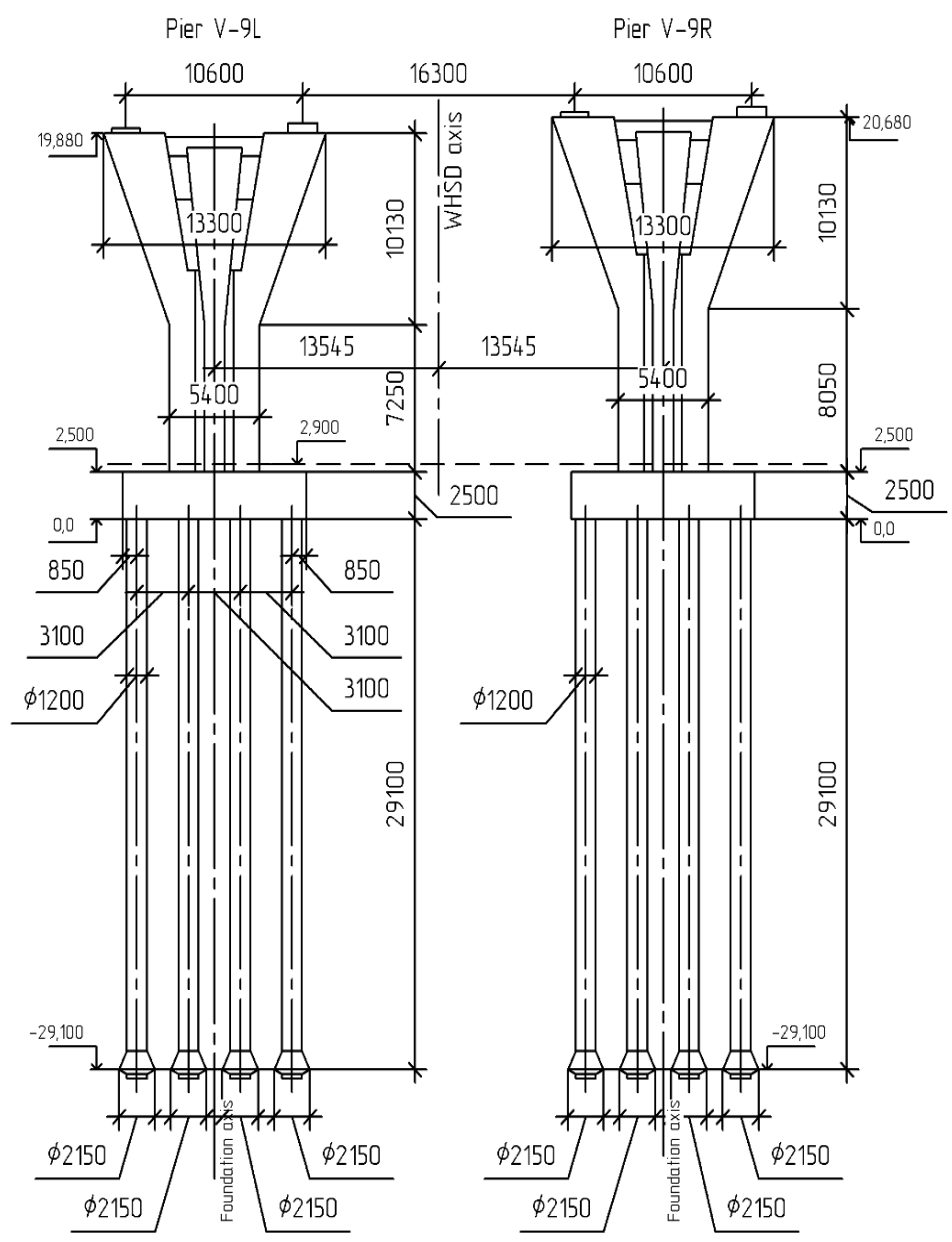

Fig. 2. Scheme of the V9 group piers foundations. 


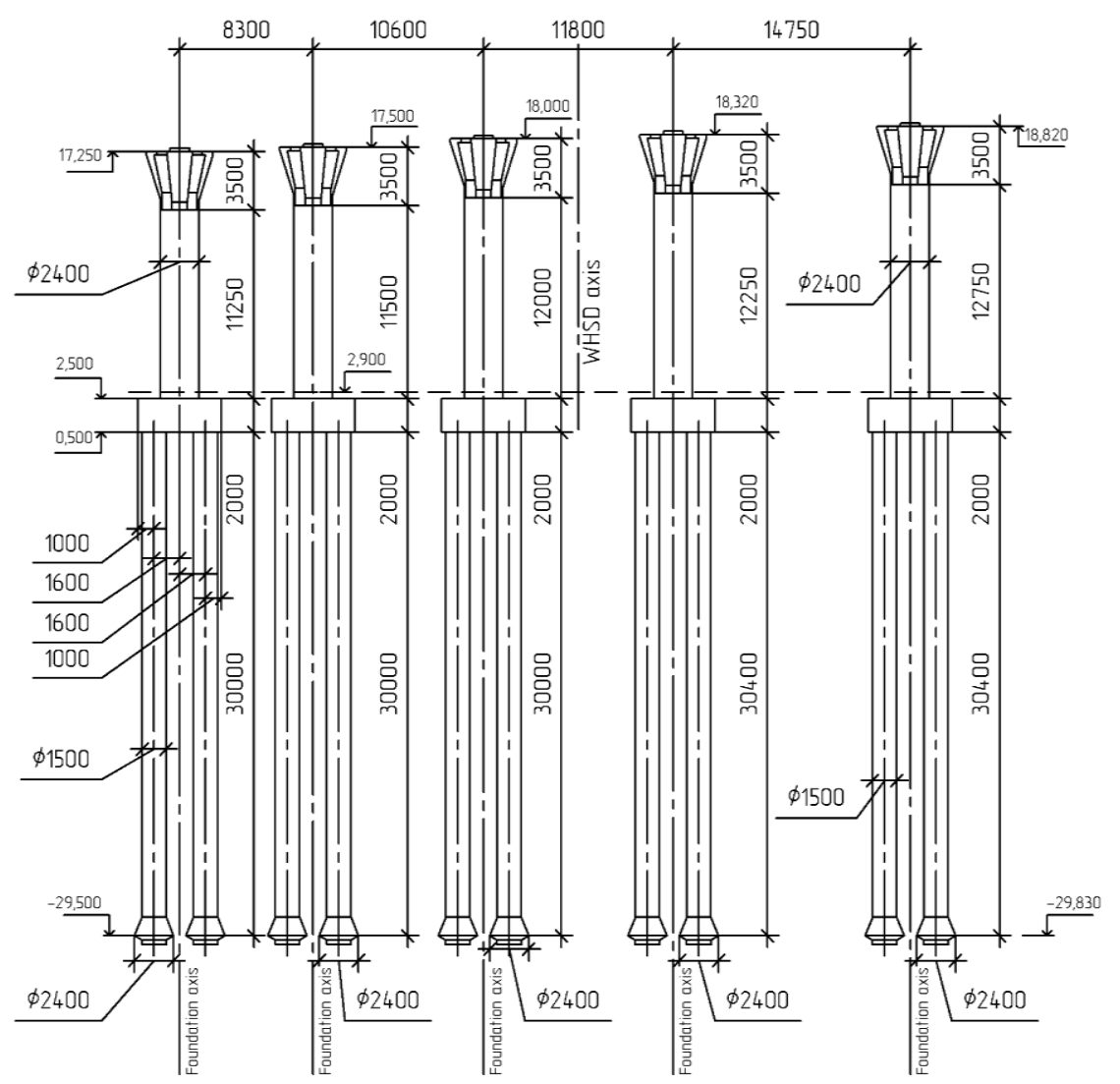

Fig. 3. Scheme of the V8 group piers foundations.

The shifts and deformations were evaluated in the Plaxis $3 \mathrm{D}$, both before tunneling (at the engineering phase) and after tunneling (for analyzing the quality of the models).

Due to the complex intersection geometry of the tunnel and the elements of the WHSD, it was decided to evaluate the shifts and deformations on 3D models. (Fig. 4). 


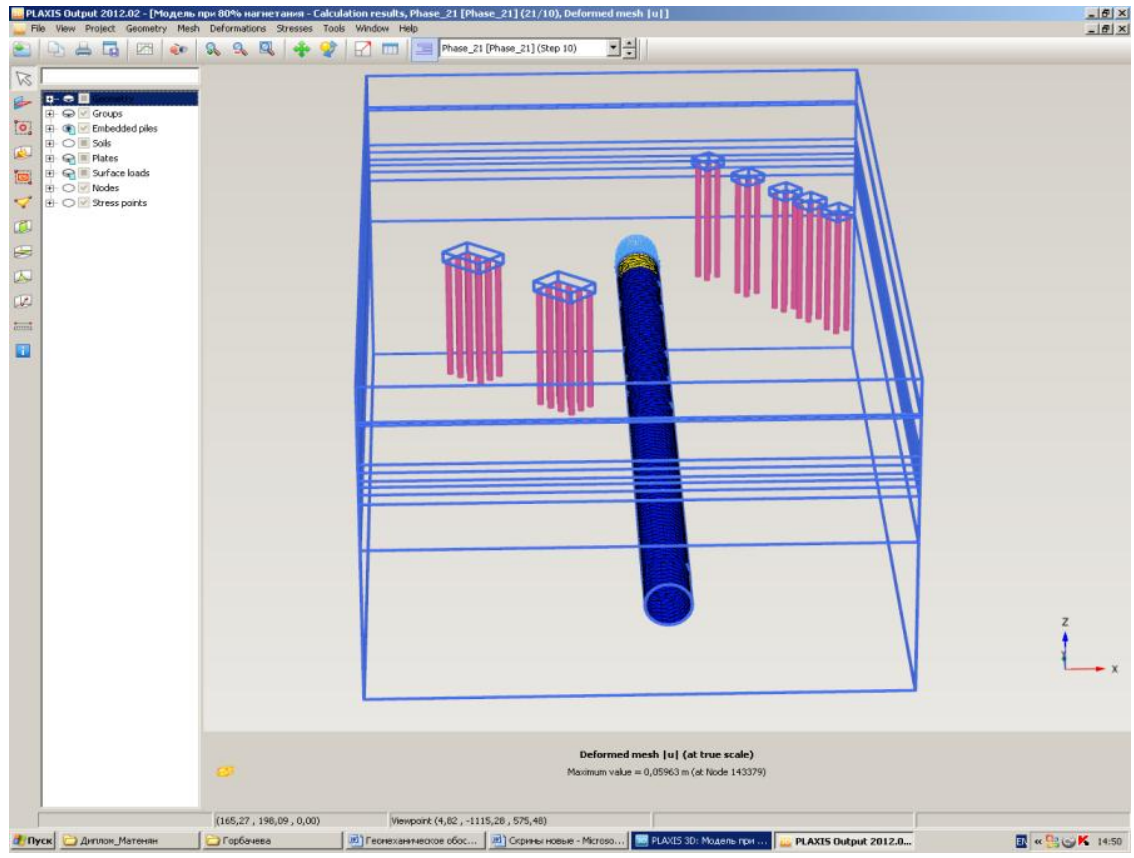

Fig. 4. Three-dimensional model in Plaxis 3D.

For simplicity, the enclosing soils were simulated by a horizontal layer of constant width (Table 1).

Table 1. Parameters of the soils.

\begin{tabular}{|c|c|c|c|c|c|c|c|}
\hline $\begin{array}{l}\text { Layer } \\
\text { number }\end{array}$ & Width, m & Name of soil & $\begin{array}{l}\text { Density } \rho, \\
\mathrm{g} / \mathrm{cm}^{3}\end{array}$ & $\begin{array}{l}\text { Module of } \\
\text { deformation } \mathrm{E} \text {, } \\
\mathrm{MPa}\end{array}$ & Poisson ratio & $\begin{array}{l}\text { Internal } \\
\text { friction } \\
\text { angle } \varphi \text {, } \\
\text { deg }\end{array}$ & $\begin{array}{l}\text { Specific } \\
\text { cohesion c, } \\
\text { MPa }\end{array}$ \\
\hline 1 & 8.7 & Inwashed soil & 1.97 & 20.0 & 0.33 & 30 & 0.001 \\
\hline 2 & 0.8 & Silica fines & 1.97 & 20.0 & 0.33 & 30 & 0.001 \\
\hline 3 & 9.6 & Clay loam & 1.92 & 6.5 & 0.40 & 13 & 0.011 \\
\hline 4 & 2.0 & Clay loam & 1.83 & 7.0 & 0.45 & 10 & 0.012 \\
\hline 5 & 2.1 & Clay loam & 1.87 & 9.0 & 0.40 & 13 & 0.014 \\
\hline 6 & 1.5 & Sandy clay & 2.21 & 17.0 & 0.32 & 24 & 0.027 \\
\hline 7 & 2.0 & Sands & 2.04 & 28.0 & 0.33 & 32 & 0.004 \\
\hline 8 & 2.4 & Loam & 2.12 & 14.5 & 0.35 & 22 & 0.027 \\
\hline 9 & 11.5 & Clays & 2.13 & 100.0 & 0.35 & 21 & 0.050 \\
\hline 10 & 51.8 & Clays & 2.23 & 200.0 & 0.35 & 22 & 0.150 \\
\hline
\end{tabular}

The pier foundations were simulated as groups of piles, united by a foundation grill. The enclosing soils and foundation grills were simulated using linear elastic soils models (Mohr-Coulomb model).

Preliminary calculations, in which the phased tunneling was simulated, showed a slight effect in the dynamics of deformations during the movement of the cut face. For this reason, to simplify the simulation, it was justified to excavate the tunnel in one phase. In 
this case, the total convergence of soils was taken into account [14]. The impact analysis of the geological and technological factors on the deformations showed the prevailing influence of technological factors. First of all, the effect of the void filling system, which fills the gap between the lining and the soil with grout, was considered. Therefore, an indicator of the grout filling degree was adopted as the main factor that affects the distribution of displacements.

To verify the models, 3 groups of simplified three-dimensional models with various degree of grout filling were created and analyzed: $40 \%$ and $60 \%$ (emergency situations), $80 \%$. According to the simulation results, uneven subsidence and tilting of the foundation grills and tilting of the WHSD structures along the supports were calculated.

The depth of the tunnel trace is 47 meters. The outer tunnel diameter is 10.3 meters, the inside diameter is 9.4 meters. The calculations were performed in three stages: calculation of natural stress fields (phase 0), calculation of displacements, deformations, and stresses after the construction of foundation grills and pile columns (phase 1), and calculation after tunneling (phase 2). To assess thedisplacementsand deformations caused by tunneling, the displacements were reset to zero after phase 1.

\subsection{Geodesic monitoring of bridge structures}

To control the undermining of the WHSD, geodesic monitoring of the displacements and deformations of piers was organized. Monitoring was based on a robotic total station. The measuring system started to work on 04.04.2017. The work was carried out by the Lenmetrogiprotrans Institute.

The measuring system included robotic total station and prisms, which were set on the piers of the WHSD (Fig. 5). First of all, the vertical components of the displacements, i.e. the subsidence were measured.

\section{RESULtS}

\subsection{The results of the geodesic monitoring}

The monitoring results showed that the shifts of pier foundations began right after the tunnel face approached the location of the bridge foundation. The development of subsidence lasted for 6-10 days. Then the displacement values stabilized within $2 \mathrm{~mm}$. Monitoring was carried out for another six months after the undermining the pier foundations. The final values of subsidence are shown in Table 2. 


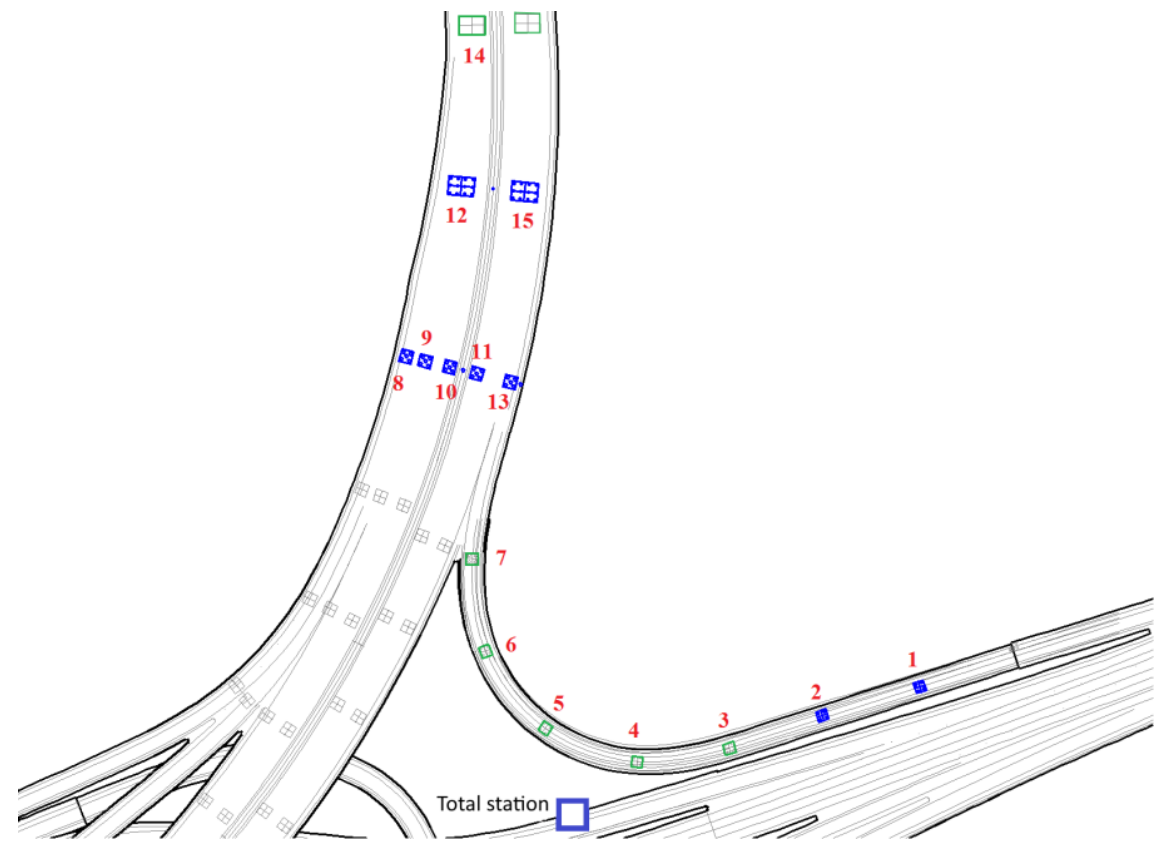

Fig. 5. Arrangement of prisms on the WHSD piers.

Table 2. The subsidence of the WHSD piers.

\begin{tabular}{lccl}
\hline $\begin{array}{l}\text { Piers } \\
\text { number }\end{array}$ & Shift start date & $\begin{array}{l}\text { Settlement } \\
\text { stabilization }\end{array}$ & $\begin{array}{l}\text { The value of } \\
\text { subsidence, mm }\end{array}$ \\
\hline \multicolumn{4}{c}{ V9-group piers } \\
\hline 12 & $05 / 19 / 2017$ & $05 / 29 / 2017$ & 14 \\
15 & $05 / 19 / 2017$ & $05 / 29 / 2017$ & 7 \\
\hline \multicolumn{4}{c}{ V8-group piers } \\
\hline 13 & $05 / 26 / 2017$ & $06 / 02 / 2017$ & 10 \\
11 & $05 / 28 / 2017$ & $06 / 02 / 2017$ & 6 \\
\hline
\end{tabular}

\subsection{Simulation results}

According to the results of the studies that were carried out during the construction of tunnels in Moscow and St. Petersburg, it was revealed that the degree of grout filling of the gaps between the lining and the soil is about $80 \%$ on average [15]. In this regard, in tunneling simulation, first of all, $80 \%$ filling of the grout was taken into account.

Piers 12 and 15 of V9 group and piers 13 and 11 of V8 group, which are closest to the tunnel axis, were the most affected by construction work (Fig. 5). Shifts and deformations of piers 8, 9 and 10 of the V8 group were not considered in this study, since the effect on them turned out to be insignificant (from $0 \mathrm{~mm}$ to $4 \mathrm{~mm}$ ). Piles and foundation grills moved almost together with the soils (contours of the soil movements near piles are almost vertical).

The subsidence distribution near piers 12 and 15 (group V9) and 13 and 11 (group V8) are shown in Figures 6-9. 


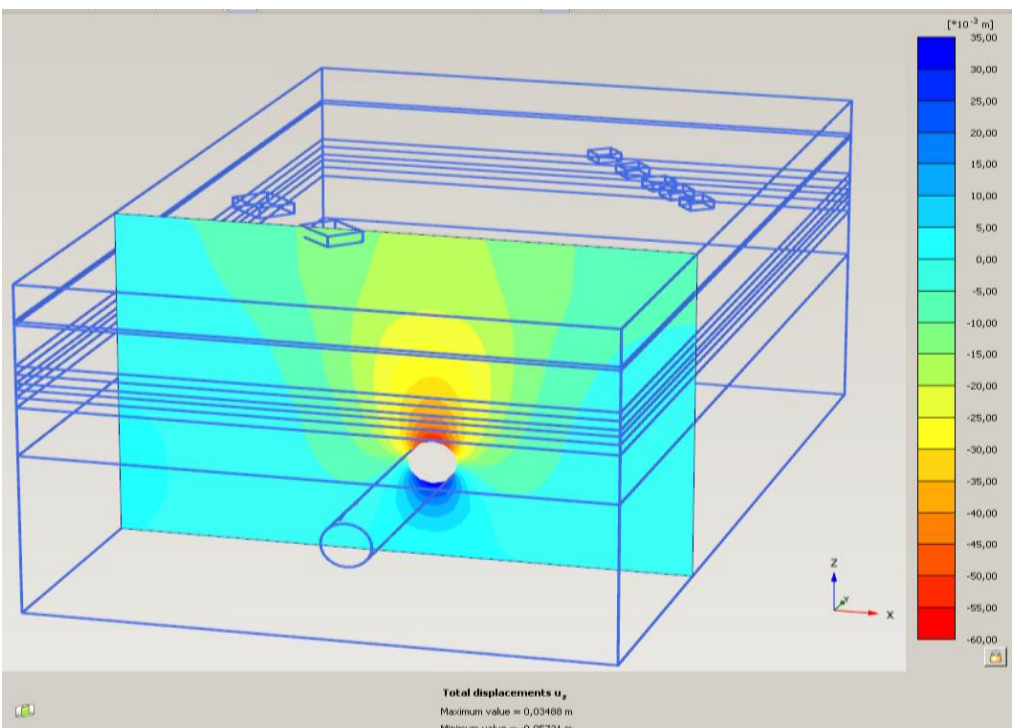

Fig. 6. The subsidence distribution near the foundation grills of pier 12 (group V9).

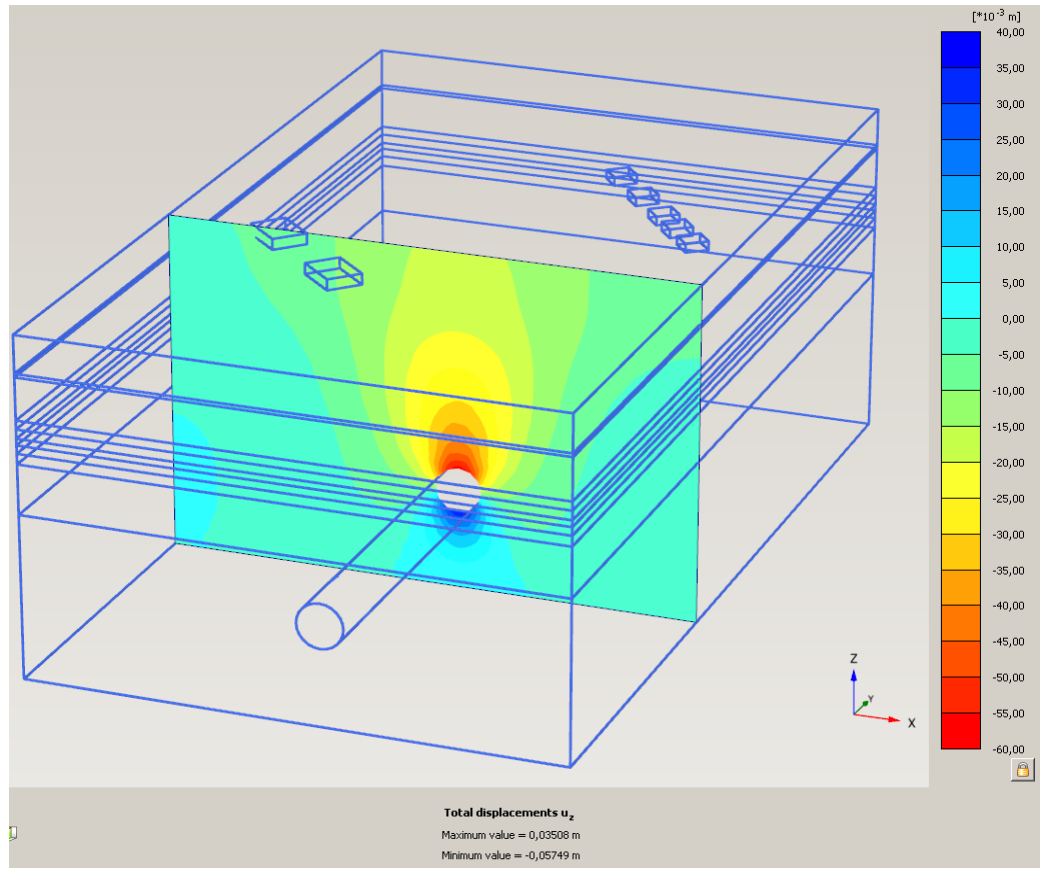

Fig. 7. The subsidence distribution near the foundation grills of pier 15 (group V9). 


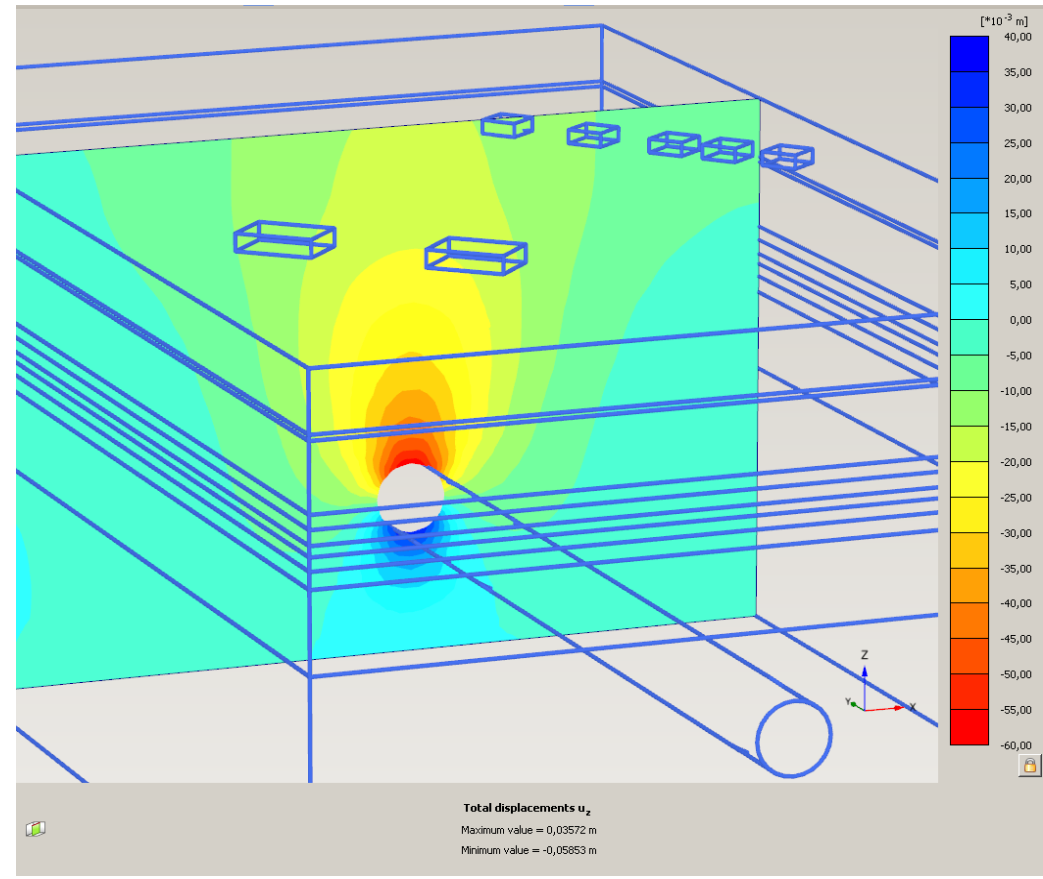

Fig. 8. The subsidence distribution near the foundation grills of pier 13 (group V8).

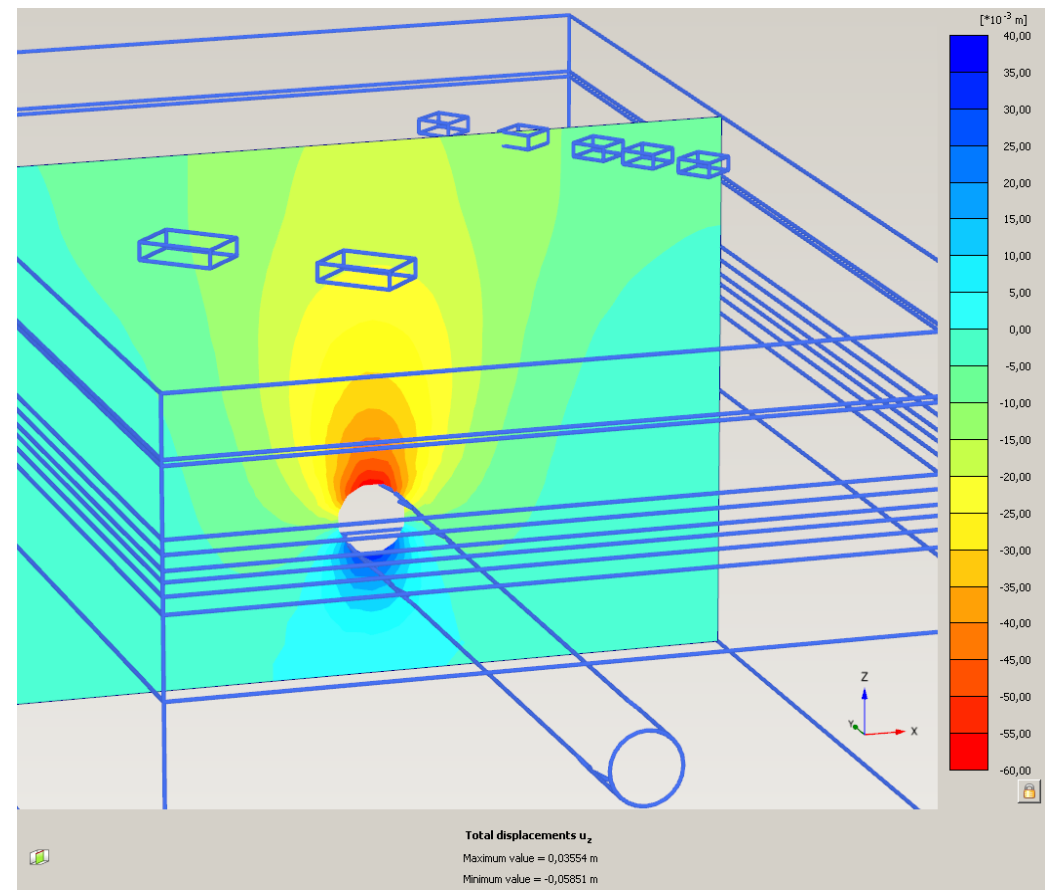

Fig. 9. The subsidence distribution near the foundation grills of pier 11 (group V8). 
The slope of foundation grills was calculated as the subsidence difference between the nearest and the farthest (relative to the tunnel) foundation grills points divided by the distance between these points. The results of the calculations of the slopes of the foundation grills are presented in Table 3 (simulation with $80 \%$ of grout filling).

Table 3. Results of the slope calculations of the foundation grills (simulation with $80 \%$ of grout filling).

\begin{tabular}{|c|c|c|c|}
\hline \multirow{2}{*}{$\begin{array}{c}\text { Number of } \\
\text { foundation grill }\end{array}$} & \multicolumn{2}{|c|}{ Subsidence of the foundation grill, mm } & \multirow{2}{*}{ Slope } \\
\cline { 2 - 3 } & Nearest point & Farthest point & \\
\hline \multicolumn{4}{|c|}{ V9-group piers } \\
\hline 12 & 14 & 10 & $0.52 \cdot 10^{-3}$ \\
\hline 15 & 8 & 6 & $0.35 \cdot 10^{-3}$ \\
\hline \multicolumn{4}{|c|}{ V8-group piers } \\
\hline 13 & 15 & 13 & $0.38 \cdot 10^{-3}$ \\
\hline 11 & 13 & 11 & $0.46 \cdot 10^{-3}$ \\
\hline
\end{tabular}

Comparison of simulation results (simulation with $80 \%$ of grout filling) and field data are presented in Table 4.

Table 4. Comparison of simulation results (simulation with $80 \%$ of grout filling) and field data.

\begin{tabular}{|c|c|c|}
\hline \multirow{2}{*}{$\begin{array}{c}\text { Number of } \\
\text { foundation grill }\end{array}$} & \multicolumn{2}{|c|}{ Average subsidence of foundation grill } \\
\cline { 2 - 3 } & Field data, $\mathrm{mm}$ & Results of simulation with $80 \%$ of grout filling, $\mathrm{mm}$ \\
\hline \multicolumn{3}{|c|}{ V9-group piers } \\
\hline 12 & 14 & \\
\hline 15 & 7 & \\
\hline \multicolumn{2}{|c|}{} & V8-group piers \\
\hline 13 & 10 & \\
\hline 11 & 6 & 12 \\
\hline
\end{tabular}

Also, calculations were made for emergency tunneling, when the gaps between the lining and the soil would be filled with grout only by $60 \%$ and $40 \%$ (Tables 5,6 ).

Table 5. Results of the slope calculations of the foundation grills (simulation with $60 \%$ of grout filling).

\begin{tabular}{|c|c|c|c|}
\hline \multirow{2}{*}{$\begin{array}{c}\text { Number of } \\
\text { foundation grill }\end{array}$} & Subsidence of the foundation grill, $\mathrm{mm}$ & \multirow{2}{*}{ Slope } \\
\cline { 2 - 3 } & Nearest point & Farthest point & \\
\hline \multicolumn{4}{|c|}{ V9-group piers } \\
\hline 12 & 27 & 19 & $1.09 \cdot 10^{-3}$ \\
\hline 15 & 15 & 10 & $0.73 \cdot 10^{-3}$ \\
\hline \multicolumn{4}{|c|}{ V8-group piers } \\
\hline 13 & 30 & 26 & $0.81 \cdot 10^{-3}$ \\
\hline 11 & 25 & 20 & $0.97 \cdot 10^{-3}$ \\
\hline
\end{tabular}


Table 6. Results of the slopes calculations of the foundation grills (simulation with $40 \%$ of grout filling).

\begin{tabular}{|c|c|c|c|}
\hline \multirow{2}{*}{$\begin{array}{c}\text { Number of } \\
\text { foundation grill }\end{array}$} & \multicolumn{2}{|c|}{ Subsidence of the foundation grill, $\mathrm{mm}$} & \multirow{2}{*}{ Slope } \\
\hline & Nearest point & Farthest point & \\
\hline \multicolumn{4}{|c|}{ V9 group piers } \\
\hline 12 & 33 & 23 & $1.32 \cdot 10^{-3}$ \\
\hline 15 & 18 & 11 & $0.88 \cdot 10^{-3}$ \\
\hline \multicolumn{4}{|c|}{ V8 group piers } \\
\hline 13 & 36 & 31 & $1.06 \cdot 10^{-3}$ \\
\hline 11 & 31 & 25 & $1.05 \cdot 10^{-3}$ \\
\hline
\end{tabular}

To assess the impact of tunnel construction on the bridge structure, the slopes of the ground structure were calculated. Such slopes were calculated as the ratio of the difference between the subsidences of two adjacent bridge piers to the distance between the centers of these piers. In these calculations, the field data was used.

An assessment of the possible impact of tunneling on the bridge piers during emergency construction was also made. It used the simulation results with $40 \%$ of grout filling. The results of the slope calculations for pairs of piers in the transverse and longitudinal (relative to the axis of the WHSD) direction are presented in Table 7.

Table 7. The slopes of the bridge structures between the piers.

\begin{tabular}{|l|l|l|l|}
\hline \multicolumn{1}{|c|}{ Interval } & Distance, $\mathrm{m}$ & Slopes (field data) & $\begin{array}{c}\text { Slopes (emergency } \\
\text { construction } \\
\text { simulation) }\end{array}$ \\
\hline \multicolumn{4}{|c|}{ Transverse slopes } \\
\hline $12-15$ & 27.760 & $-0.25 \cdot 10^{-3}$ & $-0.5 \cdot 10^{-3}$ \\
\hline $11-13$ & 14.170 & $+0.28 \cdot 10^{-3}$ & $+0.4 \cdot 10^{-3}$ \\
\hline \multicolumn{4}{|c|}{ Longitudinal slopes } \\
\hline $9-12$ & 75.580 & $+0.13 \cdot 10^{-3}$ & $+0.26 \cdot 10^{-3}$ \\
\hline $15-11,13$ & 79.890 & $-0.013 \cdot 10^{-3}$ & $-0.2 \cdot 10^{-3}$ \\
\hline
\end{tabular}

\section{Discussion}

The closest to field data were the simulation results with $80 \%$ of grout filling. The calculation results for foundation grill 15 (V9) do not differ from field data (subsidence 7 $\mathrm{mm}$ ). For foundation grill 12 (V9), the data are different by $15 \%$ (field data: $14 \mathrm{~mm}$, simulation: $12 \mathrm{~mm}$ ). However, for foundation grill 13 (V8), the difference is $30 \%$ (field data: $10 \mathrm{~mm}$, simulation: $14 \mathrm{~mm}$ ), and for foundation grill $11(\mathrm{~V} 8)$, the field data are two times lower than the calculated $(6 \mathrm{~mm}$ and $12 \mathrm{~mm})$. This indicates that there was a change in the tunneling conditions under piers 13 and 11.

During the analysis of the simulation results with different degrees of grout filling of the gaps between the lining and the soil $(46 \%, 60 \%, 80 \%)$, the slopes of the foundation grills were calculated. The obtained values turned out to be significantly lower than the limit criterion values. The maximum slope value was $1.32 \cdot 10^{-3}$, with the valid value of $5 \cdot 10^{-3}$.

The calculation of the slopes of the bridge structures (between the piers) also showed that the deformation values in this case would be negligible, even if the emergency modes of tunneling were taken into account. The maximum slope value was $0.5 \cdot 10^{-3}$. At the same 
time, it is worth paying attention to the different signs of slopes. And in a situation where the deformations can take significant values, it is necessary to consider also the curvature and twisting of structures.

\section{Conclusions}

In general, the obtained results indicate that the use of simplified models allows at a quantitative level to assess the impact of the EPB undermining on the enclosing soils and the bridge structures.

Even in extreme construction conditions (at 40-50\% grout filling and with significant subsidence), the deformation values do not reach the limit criteria (Rules for the Protection of Structures). This can be explained by deep depth construction in hard Proterozoic clays.

For large structures, such as bridges, using only subsidence values to assess the harmful effects of mining operations is unacceptable. Here it is also necessary to consider the deformations as the first and second derivatives of subsidence: the deformations of slopes, curvature, and twisting.

\section{References}

1. The regulations of the Russian Federation "Rules for the structures and natural objects protection from the harmful effects of underground mining in coal deposits" approved by the Resolution of Gogortekhnadzor of Russia dated 16.03.98 No.13: in effect since 01.10.98. Moscow.

2. The regulations of the Russian Federation "Rules for the protection of structures and natural objects from the harmful effects of underground mining in the iron ore deposits of the Urals and Kazakhstan" approved by the Resolution of the USSR Ministry of Metallurgy 2.08.90. Sverdlovsk.

3. O.V.Trushko, D.A. Potemkin, V.L. Trushko, Provision of stability of development mining at Yakovlevo iron ore deposit. International Journal of Applied Engineering Research18(11): 9248-9255(2016).

4. P.A.Demenkov, M.A.Karasev, D.N. Petrov, Predicting land-surface deformations during the construction of underground facilities of complex spatial configuration. International Journal of Civil Engineering and Technology,7(8): 1161-1171(2017).

5. A.G. Protosenya, N.A. Belyakov, N.T. Do, Development of a method for predicting the presure of the tunnel face and earth surface settlements during the construction of tunnels by mechanized tunneling complexes. Journal of Mining Institute211: 5363(2015).

6. A.G. Protosenya, M.A. Karasev, N.A. Belyakov, Method of predicting earth surface subsidence during the construction of tunnels using TBM with face cantledge on the basis of multivariate modeing. International Journal of Civil Engineering and Technology 9(11): 1620-1629,(2018).

7. A.G. Protosenya, M.A. Karasev, V.I. Ochkurov, Introduction of the method of finitediscrete elements into the Abaqus. Explicit software complex for modeling deformation and fracture of rocks.EasternEuropean Journal of Enterprise Technologies 7(6): 11-18,(2017).

8. A.P. Gospodarikov, Development of nonlinear mathematical models and numerical modeling of the forecast of the rocks stress-strain state. Journal of Mining Institute 219: 382-386,(2016). 
9. A. Franza, (2017). Tunnelling and its effects on piles and piled structures. Ph.D. thesis. The University of Nottingham. Nottingham. Franza, A., Idinyang, S., Heron, C., and Marshall, A.M. Development of a coupled centrifugenumerical model to study soilstructure interaction problems. Proceedings of the 3rd European Coference on Physical Modelling in Geotechnics. Nantes,France: 135-140,(2016).

10. Y. Chungsik, Interaction between tunneling and bridge foundation - A 3D numerical investingtion. Computers and Geotechnics49: 70-78,(2013).

11. P. Jongpradist, T. Kaewsri, A.Sawatparnich, et al. Development of tunneling influence zones for adjacent pile foundations by numerical analyses. Tunnelling and Underground Space Technology 34: 96-109,(2013).

12. C.Y.Cheng, G.R. Dasari, C.F.Leung, Y.K. Chow, Finite element analysis of tunnel-soipileinteraction using displacement controlled model. Tunneling and Underground Space Technology 22(4):450-466,(2007).

13. E.M. Volokhov, V.I. Kireeva, S.Yu.Novozhenin, Problems of rock displacements assessing during the construction of large urban underground transport structures by tunneling mechanized coplexes with active face loading. MarkshejderskijVestnik,5: 3842.(2015).

14. E.M.Volokhov, V.I. Kireeva, Analysis of the results of field studies of geomechanical process es in construction of large transport tunnels with the use of a mechanized tunnel boring complex with work face earth pressure balance in the special conditions. ARPN Journal of Engineering and Applied Sciences 12(20), 5811-5821,(2017).

15. D.V. Panfilov, The methodology for deformations prediction of the earth's surface during the construction of transport tunnels based on spatial modeling. Ph.D. thesis. Research Institute of Transport Construction. Moscow.(2005). 